\title{
Kyiv Institutional Buildings Energy Efficiency Program: Draft Procedures
}

September 1998

\section{RECEIVED \\ OCT 13 \\ O STI}

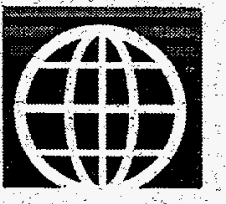

Global

Studies

Program

Pacific Northwest National Laboratory

Advanced International Studies Unit

ASTRISUTION OF THIS DOCUMENT is UNHMTED 


\title{
DISCLAIMER
}

This report was prepared as an account of work sponsored by an agency of the United States Government. Neither the United States Government nor any agency thereof, nor Battelle Memorial Institute, nor any of their employees, makes any warranty, express or implied, or assumes any legal liability or responsibility for the accuracy, completeness, or usefulness of any information, apparatus, product, or process disclosed, or represents that its use would not infringe privately owned rights. Reference herein to any specific commercial product, process, or service by trade name, trademark, manufacturer, or otherwise does not necessarily constitute or imply its endorsement, recommendation, or favoring by the United States Government or any agency thereof, or Battelle Memorial Institute. The views and opinions of authors expressed herein do not necessarily state or reflect those of the United States Government or any agency thereof.

\author{
PACIFIC NORTHWEST NATIONAL LABORATORY \\ operated by \\ BATTELLE \\ for the \\ UNITED STATES DEPARTMENT OF ENERGY \\ under Contract DE-ACO6-76RLO 1830
}

Printed in the United States of America

Available to DOE and DOE contractors from the

Office of Scientific and Technical Information, P.O. Box 62, Oak Ridge, TN 37831; prices available from (615) 576-8401.

Available to the public from the National Technical Information Service, U.S. Department of Commerce, 5285 Port Royal Rd., Springfield, VA 22161 


\section{DISCLAIMER}

Portions of this document may be illegible in electronic image products. Images are produced from the best available original document. 


\section{Kyiv Institutional Buildings Energy Efficiency Program: Draft Procedures}

September 1998

Prepared by

Pacific Northwest National Laboratory

Tysak Engineering

Prepared for

the U.S. Department of Energy

under Contract DE-AC06-76RLO 1830

Pacific Northwest National Laboratory

Richland, Washington 99352 


\section{Summary}

The Kyiv Institutional Buildings Energy Efficiency (KIBA) Project is being conducted to support the development of a program to improve the energy efficiency for heat and hot water provided by district heat in institutional (education, healthcare, and cultural) buildings owned and operated by State and Municipal Organizations in the City of Kyiv, Ukraine. KIBA is funded by the U.S. Department of Energy and is being conducted in cooperation with the World Bank and the Ukrainian State Committee for Energy Conservation.

This document provides a set of draft procedures for the installation of the efficiency measures to ensure that the quality of the installations is maximized and that cost is minimized. The procedures were developed as an integrated package to reflect the linkages that exist throughout the installation process. A brief description of each of the procedures follows:

- Audit. The audit procedure is designed to screen and select buildings qualified for the installation of measures and to specify the types and quantities of applicable measures in qualified buildings. It is anticipated that the information collected in the audit will carry through directly to the other design, installation and acceptance, and verification procedures.

- Design. The focus of the design is to provide standardized alternative configurations and designs of substation control equipment in order to minimize the time and cost involved in generating a certified design.

- Installation and Acceptance. This procedure outlines the steps for the installation and acceptance of the equipment and materials in each building to include an installation plan, site preparation, construction and assembly, commissioning and training, and an acceptance protocol.

- Verification. This procedure outlines the approach and methodology for establishing baseline energy consumption, and for analyzing and explaining any variances that occur in buildings that have undergone energy efficiency improvements.

- Process Evaluation. The Process Evaluation Procedure is designed to provide continuous feedback to the administrative and installation processes in order to retain effective practices and revise those that are not.

It is anticipated that these procedures will be revised by the Project Implementation Unit after it is formed in the fall of 1998 and as the project progresses. 


\section{Acknowledgment}

Development of these draft procedures was funded by the U.S. Department of Energy (DOE) under a Memorandum of Cooperation between the DOE and Ukrainian State Committee for Energy Conservation (SCEC). Thanks are provided to Brian Castelli and Elizabeth Arner of DOE's Office of Energy Conservation and Renewable Energy for their perseverance and leadership in this effort. Recognition and thanks are also extended to Georgy Panchenko of the SCEC and Mykola Raptsun of the Agency for Rational Energy Use and Ecology for guiding the development of this document. 


\section{Introduction}

The Kyiv Institutional Buildings Energy Efficiency Program involves the installation of energy efficiency measures in schools, hospitals, and cultural buildings owned by the Ministry of Education, Ministry of Health, and Municipality of Kyiv. This document provides a set of draft procedures for the installation of the efficiency measures to ensure that the quality of the installations is maximized and that cost is minimized. The procedures were developed as an integrated package to reflect the linkages that exist throughout the installation process. A brief description of each of the procedures follows:

- Audit. This procedure is designed as a two-step process. The first step is to screen the buildings to select only those qualified for the installation of measures and identify items to be resolved for the buildings to be considered for installation of the energy efficiency measures. The second step is to specify the information needs and processes for identifying the types and quantities of applicable measures in qualified buildings. It is anticipated that the information collected in the audit will carry through directly to the other design, installation and acceptance, and verification procedures.

- Design. The focus of this procedure is on substation control equipment as this involves the formal interaction of the participating agency, the design bureau, and district heating company. This procedure provides standardized alternative approaches for the configuration and design of substation control equipment. The primary goal is to standardize the process to minimize the time and cost involved in generating a certified design. It is envisioned that the design process can occur by directly using the data and information obtained from the audit, eliminating the need to visit each building.

- Installation and Acceptance. This procedure outlines the steps for the installation effort and sets the criteria for acceptance of the installed equipment and materials in each building. The procedure provides a description for implementing program works according to the approved design documentation that includes an installation plan, site preparation, construction and assembly, commissioning, and training. Each installation will be inspected and an acceptance protocol will be issued for each building.

- Verification. This procedure outlines the approach and methodology to be used to assess the efficiency improvement achieved. This utilizes data obtained from the audits to establish a baseline for the building population and to subsequently analyze measured energy consumption and explain any variances that occur.

- Process Evaluation. This procedure is designed to address the non-quantifiable effects of the installation process to help ensure that the installation of the equipment and the measures are of the highest possible quality at the lowest possible cost to the program. Thus the Process Evaluation is meant to provide continuous feedback to improve the administrative and installation processes.

The procedures are issued as drafts as it is anticipated that these procedures will be revised by the Project Implementation Unit after it is formed and as the program progresses. 


\section{Draft Energy Audit Procedure}

\section{Energy Audit Purpose and Objectives}

The KIBA Technical Assessment characterized the economic energy efficiency potential and investment requirements for institutional buildings owned by the Ministry of Education, the Ministry of Health, and the Municipality of Kyiv. The assessment involved a population of 1678 buildings in nine categories, three vintages, and three building size categories. The methodology modeled a sample of the population and extended the estimates to the entire population of buildings. Specific data for each building were not collected and analyzed due to the time and cost to do so, and the added usefulness of the information for assessment purposes.

It is important to recognize that the audit is the first step in the installation process and must be structured and implemented to support the building selection, procurement of materials and equipment, design, installation, acceptance, and verification activities. The audit procedure is provided in two sections:

- The first discusses the relationship of the audit to each of the activities.

- The second section provides the steps for performing the audit and the information needed in each step.

Appendix A provides a list of the data and information to be collected during the audit.

\section{Audit Relationship to Installation Activities}

\section{Building Selection Process}

Prior to the energy audit process, the building owner/administrator prepares a preliminary list of buildings to be considered for implementation in the coming heating season and will provide this list to the Project Implementation Unit (PIU). This list will be assembled from administrative and accounting information and will include limited technical data. Unless disqualified, each listed building will be audited and results of audit will be used for the design, procurement, installation, and acceptance activities. The preliminary list of buildings should contain the following information:

- Feasibility of the building for installation of particular measure(s).

- Building utilization--current and future.

- Technical aspects such as equipment sizes/quantity, potential problems with installation, risk potential for extreme costs, other foreseeable liabilities.

- Economic evaluation. (Economic evaluation assumes that the economics for given building groups will apply and will not be done for each building. Extremes will be observed and verified.)

- Other aspects, such as scheduling issues, access to the building, allowed access time, allowed disruption of activities/function. 


\section{Design Process}

The energy audit will provide initial information for the design. It is expected that the designer(s) will be provided with all necessary technical documentation and will not have to visit the site before initiating the design. The audit will provide information for the design activity to include:

- Details for the design work, such as floor plans for the substation, diameters of pipes, space and water heating capacities, drain location, electrical installation details and connections, and number, types, and sizes of windows, etc. (The appendix provides a list of the detailed audit data.)

- A set of original architectural building blueprints relevant to the efficiency measure designed. If not available, "as built" drawings/sketches will be supplied.

- A set of original blueprints for the space and water heating system including the design parameters. If not available, "as built" drawings/sketches will be supplied.

\section{Procurement}

The energy audit and economic evaluation is performed prior to a detailed design and procurement and is normally based on engineering estimates of equipment sizes and quantities, labor content, and on estimated costs. The results will be used for preliminary estimates of costs and procurement activities for planning purposes (staffing, quantity discounts, work scheduling, etc). It is important to note that the audit will not provide the information directly to the PIU for procurement purposes since the audit will not produce specification of material, parts, and equipment. Detailed information to support the procurement activity will be provided by the design activity.

\section{Verification}

The energy audit will provide all necessary baseline information for the verification of efficiency improvement to include:

- Metered baseline energy consumption for at least the 51 buildings for the 1998/1999 heating season and 180 buildings for the $1999 / 2000$ heating season $(51+129$ buildings, see the Draft Verification Plan) for the season preceding the installation of the efficiency measures. Metered data and/or accounting energy billing data will be provided.

- Occupancy and schedules prior to installation of the efficiency measures, with this information for the 51 and 180 buildings for the periods mentioned immediately above.

\section{Energy Audit Steps}

The energy audit consists of five steps for the final screening/selection of the buildings to have measures installed, determining the current energy consumption of the buildings, identifying and verifying the applicable measures and associated efficiency improvements (both technically and economically), and preparing the necessary documentation for the detailed design. 


\section{Building Selection by Owners}

The owning organization conducts an initial screening and prepares a preliminary list of buildings to be included in the investment project. Information on each building will be based on administrative and accounting information normally kept in owner's files and obtained from the administrative offices and facility managers.

First, a go/no-go decision is made based upon the responses to three questions:

- Will the building be removed from operation before the year 2010 ?

- Are there known structural or other conditions that preclude the installation and/or effectiveness of efficiency measures? If yes, describe.

- Are there other known reasons why this building should not be subject to the installation of efficiency measures? If yes, describe these reasons.

If the response to these questions is yes, the building identifier and address should be included in a no-go list with the reason(s) for not proceeding stated. Buildings rejected at this point may be reconsidered if the status changes at a later date.

Second, the preliminary list of buildings is prepared and should contain, at minimum, the following information:

- building location/address

- contact person and contact information, such as phone number(s)

- building type, purpose, and vintage

- current building use and plans for future utilization

- general condition, recent changes, and any abnormal conditions

- heat supply company and presence of heat meter

- total building floor area and type of structure.

\section{Technical Documentation}

Original, or "as built" architectural blueprints, space and water heating system piping blueprints and specification, electrical installation schemes, and other available documentation are desired. This information needs to be made available by the organization that owns the building to the audit team; if this information is not available, "as built" sketches or drawings must be generated for the design work.

\section{Initial Audit}

The initial audit will provide a second go/no-go screen for candidate buildings, verification of the technical documentation, and additional data collection. The experts performing the initial audit will collect the following information: 
- Verification of documentation as provided by the owner, note of any changes and discrepancies between the blueprints and current conditions of the building and systems.

- Overall condition of the building envelope, walls, windows, electrical installation, space and water heating system.

- Applicability of each energy efficiency measure identified in the "Technical Assessment" for the particular building. The applicability of each measure will be reviewed with respect to its need, technical difficulties with installation, anticipated additional (non-energy) works, reasonableness of installation schedule, need for disruption of building function during the installation.

- If the heat supply is metered, collection of available heat consumption data and the location of and access to the meter.

- In addition, the availability of more detailed energy consumption data means more accurate verification results; at minimum, monthly energy consumption data for electricity and natural gas must be collected. This information will be used by the verification activity to assess the presence and consumption of energy used for supplemental heating.

- When reasonable (during periods of low ambient temperature), simple measurement of indoor temperatures and overall coefficient of heat transfer for walls, windows, doors, roof, and floor above the basement will be conducted. If a heat meter is not present, primary side water flow should be measured.

- Occupant will be interviewed to provide information on indoor conditions, current problems, past problems, attempts for solutions, unusual conditions, and all other issues which could have a potential for higher cost or lower energy savings.

A no-go decision will be based on the findings of structural impediments to the installation and/or operation of efficiency measures, or other reasons found during the initial audit. The data above should be collected and preserved for no-go buildings, with the reasoning for a no-go decision clearly stated, as the buildings rejected at this point may be reconsidered if the status changes at a later date.

\section{Energy Efficiency Estimation}

An estimate of energy saving potential of applicable energy conservation measures and selected packages for each building is needed for economic evaluation of the installation. The following approaches can be used:

- Engineering estimate of energy consumption supported by conventional heat load calculations using generally accepted algorithms.

- Computer modeling, using software based on ASHRAE heat load calculation algorithms such as ASEAM or DOE-2.

- Computer modeling, using other public domain or proprietary building heat load modeling software based on generally accepted algorithms.

- The efficiency potential of selected packages of measures that were evaluated during the technical assessment task and the results can be used for determining the expected efficiency improvement. All other combinations of energy saving measures should be modeled with any proven heat load calculation method available (as described above). 


\section{Cost Estimates}

Cost estimates may be prepared based on estimated quantities of material and labor for each individual building, or based on typical calculated values per square meter of floor area, as presented in the technical assessment. The baseline for prices of material, equipment, and labor should be drawn from the Technical Assessment and should be updated periodically from the procurement activity and other experience gained in the project.

\section{Audit Report}

The information obtained by the energy audit process will be contained in an audit report.

- The report will comprise, at minimum, the following sections:

- Building Description

- Relevant Pictures

- Completed Data Tables (from the appendix)

- Applicable Sketches and Drawings

- Energy Efficiency Analysis, Costs, and Economics

- Measure Implementation Recommendations

- Appendices containing all technical details and documentation

- The report will contain detailed discussions of:

- The measures considered, measures selected, estimated cost of the installed measures (separated by material and labor), estimated efficiency improvement (in physical units and cost terms), and any special conditions and/or considerations.

- Information for the substation design including the following: design capacity, layout of connecting pipes, diameters, desired location of substation equipment, any physical restrictions (such as door size), other equipment, piping, electrical installation, availability of power, location of electrical connections, location of sensors and their wiring routing, required controls setting, special conditions such as unusual occupancy, and unusual heating system conditions.

- Information for weatherization measures. This will include information on the number, locations, sizes, and condition of windows and doors. Other information will describe caulking and/or other sealing requirements with recommended methods, materials, and quantities of materials. This section needs to clearly identify any special conditions that may impact design and/or installation.

- This information must be sufficient for the design and the designer should not be required to visit the building site, unless he/she feels more comfortable with seeing the site. 


\section{Draft Design Procedure}

The main objective of the design procedure is to provide the technical design documentation required for design approval, installation, and future reference and modification for minimum effort and at minimum attainable cost.

The design procedure is the second of a set of integrated procedures to ensure installations of the highest possible quality at the lowest possible cost. The family of procedures in this set covers audit, design, installation and acceptance, and verification.

The design procedure consists of preparation of all technical documentation for the building permits and other necessary approvals and for the installation works. Aspects of the design process include:

- Working with manufacturers and obtaining specific guidance, previous designs, components and systems installation drawings, sizing software, and other available assistance.

- Making the design as simple as practical as allowed by the standards.

- Involving of the approval agencies, district heating authorities, and prospective installation contractors.

- Compiling a database of all produced designs with an easy search/match feature.

- Ensuring time and cost reduction through replication.

The first step in minimizing the time and cost is to obtain pre-approval of the general form of the design by the organizations responsible for design approval - these include the design bureau and the district heat supplier. Once general guidance/approval is received for typical designs that apply broadly, approval of designs for individual buildings should be only a matter of checking the proper parameters (capacities, hydraulic parameters) and compliance with safety codes.

\section{General Designs}

Five general designs for the following three categories are envisioned for general approval. Schematics and discussion for each of the general designs is provided in Appendix B.

\section{Space Heating Only (SH)}

This design package will be applied to the buildings with heat supplied from the district heating company for space heating only. The two alternatives are:

- A heat exchanger based closed loop system substation that employs a single heat exchanger, which isolates the building from the district heating system.

- A 3-way valve based open system that allows the hot water from the district heat company to circulate through the building. 


\section{Space Heat and Domestic Hot Water (SH + DHW)}

This design package will be applied to the buildings with heat supplied from the district heating company for space and domestic hot water heating. The two alternatives are:

- A heat exchanger based closed loop system substation that employs three heat exchangers; one for heating and two for domestic hot water.

- A 3-way valve based open system for space heating and two heat exchangers for domestic hot water.

In both cases, a pre-heater and after-heater are required for the domestic hot water.

\section{Space Heat, Domestic Hot Water, and Ventilation (SH + DHW + HVAC)}

This design package will be applied to the buildings with heat supplied from the district heating company for space heat, domestic hot water, and mechanical ventilation. One configuration is considered:

- A heat exchanger based closed loop system substation that employs four heat exchangers; one for heating, two for domestic hot water, and one for the ventilation unit. A pre-heater and after-heater are required for the domestic hot water.

This scheme will be used for buildings with active mechanical ventilation equipment or when use of mechanical ventilation equipment is anticipated in the near future. For buildings that have provision for mechanical ventilation but do not to use it, provision will be made for future installation of a heat exchanger to serve the mechanical ventilation unit.

\section{Substation Design Process}

The substation can be designed in two parts: 1) components that can be considered standard and approximately the same in each building (which may be likened to the schematic or concept drawing), and 2) the piping that will connect the existing pipes to the new substation and will likely be different in almost every building (which may be likened to the "as built" drawing).

The design of the substation consists of the following three steps:

1. Substation type and general design. The selection of the type of substation $(\mathrm{SH}, \mathrm{SH}+\mathrm{DHW}$, $\mathrm{SH}+\mathrm{DHW}+\mathrm{HVAC}$ ) and the general design will be performed by the customer (participating organization) and the designer. Specification of the capacities and technical parameters (temperatures, water flow in the secondary loop, pressures, etc.) and all required options (pump sizes, controls, and optional equipment) will be done by the designer. Specific information regarding the manufacture specifications is not required in this step. 
2. Sizing and design of the substation system subassembly. The substation system subassembly includes the main "package" of equipment and all components required for the substation to function, but does not include the connecting piping between the existing pipes and this "package." This means that this package may be designed generally, without reference to any particular building for 3-way valve and heat exchanger based systems that come as pre-assembled units or require field installation. The subassemblies of the five general designs will be "pre-designed in advance" and $\mathrm{CAD}$ drawings will be generated by the designer or provided by the manufacturers, if available.

A discussion of the proposed design process for preassembled and field assembled subassemblies follows:

Field assembled heat exchanger system. This subassembly will be pre-designed by the design agency for different capacities and for different alternatives reflecting available space in the substation room. Special cases requiring non-typical arrangement (small space, conflict with other installed equipment, etc.) will not be pre-designed and will be handled as special cases requiring specific designs. All designs will be saved in a database and used for replication for other buildings. Designs will be sorted in the database by: a) $\mathrm{SH}, \mathrm{SH}+\mathrm{DWH}, \mathrm{SH}+\mathrm{DWH}+\mathrm{HVAC}$, b) capacity, c) options, d) special arrangements. Designs of each substation may or may not be prepared in advance; they may be designed and sorted "in real time," during the process.

Field assembled 3-way valve system. This subassembly will be pre-designed in the same manner as the heat exchanger based system described above. It is anticipated that the system will be designed and specified for different parameters (capacity, flow ranges, pressures, etc.) and for several arrangements of the existing piping. The mutations of this design will also be filed in a database and re-used with minimum modification.

Pre-assembled heat exchanger based substation equipment. Pre-assembled substation designs will be provided by the manufacturers in all available sizes or, if not available, will be prepared by the design institution. It is anticipated that manufacturers will work with the design office and provide the optimum selection of sizes to cover the project applications. Packaged substations of different manufacturers may have different connection dimensions and the design must be modified for each of the manufacturers to ensure competitiveness of the process. The design institution must contact each manufacturer, obtain the dimensions of the equipment, and decide on the number of design mutations for each size. If possible, an effort should be made to have the manufacturers comply with a "standard" dimension.

3. Pipe-fitting or As Built design. This step involves design of the piping between the substation subsystem described above and the existing piping. It must show the removal of the old system, connecting modifications on the old system, and location of the substation package. This part of the design will likely be prepared for each building with the transition from the schematic to the as built stage; however, it is desired that the process be standardized to the maximum extent possible to facilitate compliance and approval. Each design should be filed in a database and reused as much as practical. 
It is anticipated that the design will be performed by a different design office for each of the participants. However, it would be beneficial if all designs are located in a common database shared by all the involved design offices. This may be accomplished through the maintenance of a database by the PIU.

\section{Action Plan}

Through the end of calendar year 1999, six actions are recommended as follows:

1. Each of the participants will enter into contract with the design agency of their choice and set the design ownership issues in written form.

2. Several (10) buildings will be audited and selected for the implementation, and information will be given to the design agencies (see Audit Procedure).

3. The design institution(s) will prepare specifications for the selected buildings and will contact the manufacturers of substation equipment and request either assistance with sizing the equipment or release of their sizing software. The manufacturer's installation drawings will also be requested.

4. The design institution(s) will review the design with the approval agencies and obtain agreement on minimum requirements for approval. Local contractors will be contacted for consultation of minimal requirements on the design for the installation works. Then the design will be prepared accordingly and approvals will be obtained. CAD drawings of the architectural changes (if any), mechanical assembly, electrical installation, and controls will be delivered in electronic form to PIU.

5. The PIU will organize a database of the designs and will establish means for data transfer (local network, Internet connection, and/or personal contact).

6. The process will be verified and improved as needed during the installation of buildings for the $1999 / 2000$ heating season. 


\section{Draft Installation and Acceptance Procedure}

\section{Installation}

Installation is the process of implementing the project works according to the approved design documentation prepared by the participating organization that is provided to the installation contractor. The approved design includes all of the necessary planning for site preparation, construction and assembly of works, proper functioning and commissioning of equipment/materials, and necessary testing and training of the operators. Each installation will be accomplished by a contractor(s) in cooperation with the participating organizations and includes the following steps:

\section{Installation Plan}

Prior to on-site installation, the contractor will prepare an installation process plan for each building. The installation process plan will be submitted to the PIU for approval and will include:

- Installation time schedule demonstrating reasonableness of required installation time; synchronization with allowed length and timing of disruptions to building functions.

- Optimal grouping of retrofitted buildings according to the location and other factors influencing the installation cost, such as management, equipment and personnel relocation, etc.

- Technical specification of all parts and materials including material safety data sheet.

- Qualifications of technical personnel performing the work.

- Qualifications of all subcontractors.

- Management plan including progress review schedule, inspection of sites, and problem management.

- Interaction with the building occupants and operators (contact person, building access, etc.).

- DHW supply disruption plan and, if necessary, the alternative supply.

- Cost control and management plan for unexpected events.

- Continuous quality management plan.

\section{Site Preparation}

The contractor will be responsible for site preparation required for implementing the project. If necessary, site preparation will include securing access, installation of temporary water supply, cleaning, etc. The contractor will not be responsible for major changes to the building walls, installation of drains, or any other costly items that would normally be addressed within building maintenance functions. The need for maintenance items will be identified during the audit. Their implementation will be designed and performed prior to the installation of equipment/materials under the efficiency program.

\section{Construction and Assembly Works}

The contractor will be responsible for performing all equipment construction and on-site assembly and for all work required to complete the project. The construction will be organized according to the approved installation process plan. The workmanship quality will be managed continuously and also randomly. 
The contractor will have available all required construction equipment, tools, transportation, scaffoldings, safety equipment, measuring equipment, and miscellaneous installation materials. Work must be performed according to all work safety and health hazard safety requirements in Ukraine.

\section{Commissioning}

The installed equipment must be properly commissioned prior to acceptance. Commissioning will be performed by the installation contractor and will include workmanship and material quality inspection, compliance with design, and where applicable, shakedown and short-term endurance tests.

Commissioning must be done, in any case, prior to the beginning of the heating season.

\section{Training}

The building operation and maintenance (O\&M) personnel and/or the maintenance company for each building, will be properly trained to ensure the quality of O\&M work. When required, O\&M manuals and specification sheets will be provided to the maintenance personnel. Training may be organized by the contractor or supplier (manufacturer) of the equipment/materials for larger groups of O\&M staff or individually for each building after the commissioning of the equipment. Continuing education will be planned for new personnel and for retraining purposes.

\section{Acceptance Procedure}

Prior to releasing the final payment to the contractor, each installation site must be accepted by the PIU designated experts in cooperation with the participating organization. An acceptance approval document will be issued for each site complying with all requirements. For sites not meeting the acceptance criteria, the contractor will be required to remove all deficiencies and duly commission the installation in a time schedule determined by the PIU and participating organization. Only a schedule not disrupting the building occupancy or extending beyond the heating season will be allowed. The acceptance procedure will require, at minimum, the following items be inspected and approved:

- Compliance with the approved design and specification.

- Compliance of performed works with all applicable performance and safety codes. All code requirements will be stated in the design documentation.

- Verification of obtained approvals. The acceptance protocol must include all documentation of approvals for operation, metering, safety (fire, electrical, environmental, etc.).

- Approved commissioning of heat meters and equipment by the district heating company.

- Performance verification. Each site will be inspected for proper, reliable, and efficient operation and compliance with the design parameters.

- Overall quality of the installation.

In addition to the acceptance protocol, a random sample of installations will be subjected to a detailed performance observation during the heating season. This observation should reveal minor, obvious faults in design or installation procedures. Energy efficiency performance testing will be done during a separate activity and will be performed during the heating season following the installation. 


\section{Draft Energy Efficiency Verification Process}

\section{Goals}

Quantification of achieved efficiency improvement is an important part of the project. The borrowers and investors will want to know whether the investment is performing as expected and whether the planned efficiency improvements are achieved. The technical experts who calculated the performance of installed measures are interested in the project results, which will allow them to verify the reliability of calculation methods and assumptions, identify the benefits for future projects, and improve their ability to predict efficiency improvements.

The proposed verification process was formulated to achieve these goals with reasonable accuracy while keeping the process easy to implement, easy to understand, inexpensive, and not burdensome (financially or reporting).

Verification of energy efficiency improvements is a very difficult and complex task. The achieved reduction in energy consumption depends on many parameters:

- The quality and accuracy of assumptions, calculations, and estimated efficiency improvements in the audit.

- The quality of the installed measures/equipment.

- The quality of the workmanship to install the measures/equipment.

- The ability to account for any changes in energy consumption due to changes in occupancy, physical changes to the building, and climatic conditions of a given year.

- The accuracy of the energy use evaluation/verification methodology used to quantify the achieved efficiency levels.

- The accuracy and completeness of measurements on which the verification analysis is based.

To the extent possible, variability of many of these factors will be controlled by an integrated package of procedures. Other procedures are being developed for the audit process, the design process, and the installation and acceptance process. The procurement process will ensure that quality measures/equipment are supplied and installed and a process evaluation component will identify nontechnical factors, such as occupant behavior, that may impact the achievable efficiency gains. The integration of these procedures and information will be one of the responsibilities of the PIU. 
This discussion provides the basis for a verification plan for the retrofit of institutional sector buildings as identified in the Technical Assessment and the Lending and Implementation Assessment (PNNL-11644. and PNNL-11653, respectively). It is expected that this plan will undergo further development by the PIU at the direction of the Inter-Agency Work Group as the definition of the project continues.

\section{Verification Process}

Energy efficiency improvements are defined as the difference between the energy consumption prior to and after installation of the energy efficiency measure. Therefore, it is important to establish baseline energy consumption for each building under the existing conditions and to perform energy consumption measurement after the installation.

It is obvious that the energy consumption during each particular heating season is dependent on several factors, such as changes in building occupancy, schedule, and weather. These factors affect the total energy consumption together with energy consumption reduction by the efficiency measures. To evaluate the direct effect(s) of the efficiency measures, the effects of other factors must be eliminated through engineering or calculation methods, and all parties involved must have a full understanding of and agree with the evaluation methods.

Evaluating performance of energy conservation measures may be very difficult and sometimes highly misleading if not completely understood. To establish a reliable means of evaluating energy efficiency investments, the U.S. Department of Energy developed the North American Energy Measurement and. Verification Protocol (NEMVP) (DOE 1996). It is recommended that the "Whole-Facility Or Main Meter Measurement" option as described in the NEMVP (DOE 1996) be used. With the NEMVP WholeFacility framework, a statistical or multivariate approach is the most expedient, but an engineering or combination approach may be necessary in some cases. The reader is referred to "The Impact of Market Transformation on DSM Evaluation Techniques," by D.A. Kitchin (in Energy Program Evaluation: Uses, Methods, and Results, Proceedings of the 1993 International Energy Program Evaluation Conference, Chicago, CONF-930842) for a discussion of these approaches.

Retrofit of each building involves several efficiency measures, such as the substation controls, heat meters, weatherization materials, radiator reflectors, faucet aerators, low-flow showerheads, and ceiling fans. Many of these measures are interactive, and when installed together, it may not be possible to establish their individual impact on energy savings (in other words, it is not possible to assign precisely the percentage of energy efficiency improvement due to each particular measure). Therefore, it is recommended that verification of efficiency improvements be performed for the entire package of measures installed in the building. 


\section{Data Collection}

Collection of data is necessary for the verification process; it is recommended that, at minimum, the following data be collected:

- Heat consumption from the heat meters installed. This data could be collected once or twice daily by the maintenance person assigned to the individual building or an automated data collection system that would permit the collection of more frequent consumption intervals, say hourly. At least twice daily is recommended with the readings timed to occupied and unoccupied periods to enable reductions attributed to controls to be reflected. It is also recommended that more frequent readings, either manual or automated, be taken for a subset of buildings to enable more detailed analysis.

- Electricity and, if applicable, natural gas consumption to enable identification and analysis of the potential supplemental heating.

- Building occupancy (say average per month) during occupied and unoccupied periods and the general hours of operation or occupancy.

- Any changes in building function and/or operation.

- Indoor temperature at multiple points to evaluate system balancing and control strategies.

- Outdoor temperature, wind speed, humidity, and solar radiation to enable proper data normalization. It is recommended that a weather station be installed to collect this data rather than rely upon other sources to avoid delays and, a weather station installed in Kyiv will provide more representative data than data collected at a more remote location.

- Occupant response to retrofits - opinion and behavior.

It is recommended that a subset of the buildings be measured prior to installation of the efficiency measures (retrofit) in order to develop a baseline to better evaluate the achieved reductions in energy consumption. Table 1 provides the suggested installation schedule of heat meters and efficiency measures by building type and heating season. Prior to installation of efficiency measures in the first year (for the 1999/2000) heating season, data is collected from a number (at least 51) heat meters installed prior to the project. And, prior to the installation of efficiency measures for the 2000/2001 heating season, a subset of these buildings (at least 129) have heat meters installed in advance of the 1999/2000 heating season.

This provides for a sequence of activities to support the verification process as follows:

- Prior to the $1999 / 2000$ heating season, selection of 101 buildings to be installed (retrofitted) for the 1999/2000 heating season to include at least 51 buildings that have had meters installed and read for the 1998/1999 heating season (these buildings will have had meters installed independent of and prior to the discussion of the program). 
Table 1. Proposed Installation Schedule of Heat Meters and Measures by Customer and Heating Season to Support Verification

\begin{tabular}{|c|c|c|c|c|c|c|c|}
\hline \multirow{2}{*}{$\begin{array}{l}\text { Installation } \\
\text { Of: }\end{array}$} & \multirow{2}{*}{$\begin{array}{l}\text { Pre-installed } \\
\text { Baseline }\end{array}$} & \multicolumn{6}{|c|}{ Installed in Period Prior to Heating Season } \\
\hline & & $1999 / 2000$ & $2000 / 2001$ & $2001 / 2002$ & $2002 / 2003$ & $2003 / 2004$ & Total \\
\hline \multicolumn{8}{|l|}{ Heat Meters } \\
\hline Ministry of Educ & 8 & 32 & 44 & 67 & 67 & 68 & 286 \\
\hline Ministry of Health & 3 & 8 & 13 & 19 & 19 & 19 & 81 \\
\hline Municipality of Kyiv & 40 & 139 & 209 & 309 & 309 & 305 & 1311 \\
\hline Total & 51 & 179 & 266 & 395 & 395 & 392 & 1678 \\
\hline \multicolumn{8}{|l|}{ Efficiency Measures } \\
\hline Ministry of Education & -- & 17 & 67 & 67 & 67 & 68 & 286 \\
\hline Ministry of Health & - & 5 & 19 & 19 & 19 & 19 & 81 \\
\hline Municipality of Kyiv & -- & 79 & 309 & 309 & 309 & 305 & 1311 \\
\hline Total & -- & 101 & 395 & 395 & 395 & 392 & 1678 \\
\hline
\end{tabular}

- In the PRE INSTALLED BASELINE column, 51 of the 101 buildings scheduled for installation of measures in the 1998/1999 heating season have heat meters installed and read for the 1998/1999 heating season.

- In the 1999/2000 column, the remaining 50 of the 101 buildings scheduled for installation of measures in the 1999/2000 heating season have heat meters installed and 129 of the 395 buildings scheduled for installation of measures in the 2000/2001 heating season have heat meters installed (100 Ministry of Education buildings, 23 Ministry of Health buildings, and 6 Municipality of Kyiv buildings).

- In the 2000/2001 column, heat meters are installed in the remaining buildings scheduled for installation of measures prior to the $2000 / 2001$ heating season.

- In the 2001/2002, 2002/2003, and 2003/2004 columns, heat meters are installed at the same time as the other measures.

- To the extent possible it is recommended that heat meters be installed in at least some fraction of the building at the beginning of each heating season.

- For the 1999/2000 heating season, install heat meters in and collect data for at least 129 of the 395 buildings scheduled for installation of efficiency measures for the 2000/2001 heating season.

- Following the 1999/2000 heating season, estimate the baseline model(s) using the two years of pre-retrofit data for the 51 buildings and one year of pre-retrofit data for the 129 buildings.

- Following the 1999/2000 heating season, compare the consumption of the 101 retrofitted buildings with the estimated baseline model(s) and the metered consumption for the 51 buildings pre- and post-retrofit. Adjust the model(s) as necessary and complete the verification of the buildings retrofitted for the 1999/2000 heating season.

- Following the 2000/2001 heating season, compare the consumption of the 395 retrofitted buildings with the estimated baseline model(s) and the metered consumption for the 129 buildings pre- and post-retrofit. Adjust the model(s) as necessary and complete the verification of the buildings retrofitted for the 2000/2001 heating season.

- Following the 2001/2002, 2002/2003, and 2003/2004 heating seasons conduct the verification for the buildings retrofitted in the respective heating seasons.

Coupled with the collection of daily data, it is suggested that a subset of the buildings (about 50 buildings with control systems installed for the 1999/2000 heating season) have the control systems enabled and 
disabled periodically to enable the verification of the energy use reduction that occurs in unoccupied periods due to temperature setbacks. This will provide for a more robust verification of the efficiency improvements.

\section{Calculating Efficiency Improvement}

A statistical estimation procedure, supplemented by an engineering approach, is recommended. In the statistical approach, baseline consumption would be specified as a function of building size, operating hours, occupancy, outdoor temperature, and perhaps other factors specific to the building type. The postinstallation (of the efficiency measures) consumption would then be specified similarly to reflect change(s) in the behavior of consumption to the energy efficiency measures.

Significant deviations between actual and modeled baseline and post efficiency improvement consumption would be examined in detail by the cognizant PIU and verification staff. Experience indicates that deviations are to be expected due to the many factors mentioned that may impact measure performance. The importance of controlling, to the extent possible, and obtaining information about these other factors cannot be overstated. It can be anticipated that engineering-based methods will be required to resolve and explain anomalies. The pre- and post-retrofit data collected for the 179 buildings scheduled to be retrofitted for the 1999/2000 and 2000/2001 heating seasons will enable the development of the more detailed data to ensure that the verification accounts for and is able to explain these other factors.

\section{Related Verification Data and Results Applications}

The metered consumption data will also be used in the following activities to maximize energy efficiency improvements and ensure persistence through the following:

- Audit. To support the calibration of computer models and improve the accuracy of the energy audits of the individual buildings.

- Models. To support the calibration of computer models and reliability of their application.

- Incentives. To support the award of incentives (based on the verification) provided to organizations to foster participation.

- Training. To support the structure and content of training programs developed for and provided to building management staff.

- Operations and Maintenance. To support feedback provided to building management staff on the effects of day-to-day operations. 


\section{Draft Process Evaluation Procedure}

\section{Overview}

The Process Evaluation is designed to address the non-quantifiable effects of the installation process to help ensure that the installation of the equipment and the measures are of the highest possible quality at the lowest possible cost to the program. Thus the Process Evaluation is meant to provide continuous feedback to improve the administrative and installation processes.

It is to be understood that the Process Evaluation findings are intended as a constructive forum to improve the efficiency and quality of the program and installations. In fact, the Process Evaluation is to highlight the retention of successful actions as well as to constructively promote correction for less successful actions.

Information and data will be collected through surveys and informal interviews with PIU staff, municipal staff directly involved in administering the program, building/facility administrative and operations management staff, and occupants. The findings and corrective actions will be tabulated and analyzed for presentation to the Steering Committee on a periodic basis.

\section{Potential Survey Groups}

Program Administration

Installation Personnel

Building/Facility Administration and Operation

Occupants

\section{Principal Subjects of Inquiry}

Administrative procedural transparency - participant's understanding of goals, benefits, and resources associated with the program

Design/installation process - effectiveness of building data for engineering, speed and responsiveness of design work, the installation process itself, component/assembly supply issues

Post-installation support - Frequency and quality of follow-up support, any additional program insights gained during the verification phase

\section{Survey Participants}

Program Administration - Municipal administrative, oversight, and PIU staff will be continuously surveyed for the effectiveness of overall program implementation. 
Installation Personnel - Design engineers and management will be surveyed at the close of each installation project. The purpose of this survey group is to maximize the quality of the installation, while minimizing future program costs.

Building/Facility Administration and Operation - This survey group will provide information on training, support, and any incentive programs to ensure program persistence.

Occupants - The group will contribute to an understanding of baseline energy awareness, program expectations, and other information to reduce stress/uncertainty and improve training and/or information materials.

\section{Survey Periodicity and Content}

Initial Contact - This survey is designed to evaluate the participant's knowledge of their facilities' energy consumption patterns, energy efficiency, and fuel/electricity billing. Additional questions may be added, at the request of the participating ministry.

Walk-through Contact - Periodic walkthrough of selected facilities to assess the non-quantifiable impacts of installed equipment. Items should include the occupant expectations, changes in occupant comfort levels, disruptions during installation, and suggestions that may make the installation process more efficient and constructive.

Post-Installation Survey - Once the energy-efficiency improvements have been installed, each participant will complete a second questionnaire to gauge both general and specific opinions of the program.

Additional feedback may be collected and maintained from:

Phone contacts to the Center

Walk-in contacts

Notes from any discussion with Ministry representatives.

\section{Program Evaluation Report(s)}

It is suggested that the program be evaluated biannually with a written and oral presentation provided to the Steering Committee. It is also suggested that the Process Evaluation activity be the focus for this reporting to gather the information from the other installation and administrative activities. The purposes are to provide continuous feedback on the efficacy of each phase and to identify obstacles that require greater focus from the Project Implementation Team. 
Central to the evaluation report are three key questions:

la) Is the program progressing at the anticipated rate?

b) If not, what steps must be taken to rectify the schedule.

2a) Are the performance and cost of the efficiency improvements in line with the estimates?

b) If not, what aspects are working well and what are the suggested corrective actions?

3a) Are the program administrative and delivery procedures consistent with the goal of minimizing cost and maximizing the performance of the installations?

b) If not, what is working well and what are the recommended corrective actions?

In addition to answering these questions, the periodic evaluation report should address other areas that are working well and other suggested improvements. 


\section{Appendix A}

\section{Audit Data Description}

The following is a description of the energy audit procedure and the information expected for each building from that procedure.

\section{General Information}

- Building address, location.

- Facility contact person, telephone number, best time for contact.

- Building owner/administrator contact person, telephone number, best time for contact.

- Building category and subcategory.

- Building general description (single/multi-story, construction materials, general condition of the facility).

- Vintage (pre-58, 58-80, post 80).

- $\quad$ Size (less than 3 story, 3-4 story, more than 4 story).

- Total and heated floor area.

- Floor plans (for each floor).

- Energy consumption data for space and water heating by month for the past year.

- Energy consumption data for electricity and natural gas consumption for the past year.

- Recent changes in occupancy, and past or planned improvements.

- Typical/average occupancy by month (number of people and schedule).

- Interview with occupants regarding indoor conditions during cold weather, building abnormalities, known problems, and suggestions for solutions

\section{Weatherization Information}

- Number of windows and total fenestration area.

- Detailed dimensions of each window size/style, including pictures and/or drawing of each size/style.

- Number of windows requiring parts replacement for each window size and style.

- Quantity of each material group (seals, silicone, paint, other supplies).

- Need for special equipment (such as scaffolding, crane, safety rails, etc.).

- Special conditions (related to safety, building use schedule, clean environment requirement).

- Inspection of window conditions, including "health" of window frame material, need for installation/replacement of glass and hardware, need for paint removal/repainting.

\section{Radiator Reflector Information}

- Feasibility of the installation (some types of radiators, such as finned compact coils, are not the type conducive to this measure).

- Sizes (dimensions) of radiators and quantity of each size. Total area behind radiators.

- Accessibility of wall behind radiator (is there room for direct installation of reflective material or does the radiator have to be removed). If it is necessary to the remove radiators, how many and what is involved (draining water, corroded or damaged connection, need for replacement/spare parts).

- Are there room-side covers to be removed for installation. If yes, how many and what is involved. 
- Wall conditions behind the radiators (is there a need for resurfacing, painting, is the wall suitable for installation), what wall material (it may be different than masonry wall, such as wood or plastic).

- Special conditions (access to the rooms, need to notify the occupant).

\section{Ceiling Fan Information}

- Feasibility (esthetical issues - will the fan fit the decor of the space, will it provide sufficient air movement, is it necessary, is the ceiling height sufficient, are there any obstructions for access, any special conditions).

- Size and quantity of each.

- Location of fans and control switches.

- Room size (floor area dimensions, ceiling height).

- Heating system type, locations of heating elements (sketch).

- Measurement of air temperature stratification during heating season, occupied and unoccupied (best done by test instrument installed for a sufficient period).

- Electrical wiring (on the wall, inside the wall, external).

- Availability of electric power (distance from location, accessibility).

- Special equipment requirement (scaffolding, safety rails).

- Typical room occupancy, capacity, and schedule.

- Typical conditions in the room during occupied period and any general problems.

- Presence and use of other ventilation systems.

\section{Heating System Information}

Drawings will be required to size and locate the substation and all electrical and controls connections these will include drawings of the plans for the substation location and layout, the electrical installation in the substation, and of the heating system by floor. The audit will use a general schematic drawing with "blanks" to be filled in to provide the necessary notes for sizes and capacities of the new equipment.

Substation:

- Required capacity for space heating and domestic water heating.

- Number of substations (some buildings may have multiple substations in different locations).

- The presence of a two- or four-pipe system.

- The diameter of the space heating pipes and determination of sufficiency for space and water heating.

- General conditions of pipes and a determination of the need for replacement.

- Pipe diameters both for primary and secondary circuits.

- Location of substation, identification of connection points for the primary and the secondary pipes (to determine where to cut the existing pipes and connect the new substation)

- Electrical connection - location, available power, panel space.

- Required electrical parts, such as circuit breakers, wires, and other installation materials.

- Location of indoor and ambient sensors, and location of control panel.

- Location and accessibility of heat meter to the facility manager and billing company.

- The need to retrofit/install the drain, drain length, parts quantity, and assessment of any problems with the drain installation. 
Building heating system:

- Date when the heating system was last chemically cleaned.

- Inspection of the heating system - conditions, sufficient capacity, proper flow in the pipes, clogging, any problems (documented and undocumented).

- Sufficiency of air purging, need for of installation of air purgers and/or air separator(s).

- Condition and need for replacement of radiator valves and other system parts.

- The existence and condition of balancing valves; quantity of new valves required.

\section{Hot Water Heat Exchangers Information}

This activity will be done together with the space heating substation audit, and the space heating and domestic water heating will be designed as one "package."

- Required capacity for domestic water heating.

- Number of domestic hot water systems (some buildings may have multiple domestic hot water heat exchangers in different locations).

- The diameter of the space heating pipes and determination of sufficiency for space and water heating.

- General conditions of pipes and a determination of the need for replacement.

- Pipe diameters - primary and tap water sides.

- Location of heat exchanger, identification of connection points for the primary side and the tap water pipes (to determine where to cut the existing pipes and connect to the new heat exchanger).

- Electrical connection - location, available power, panel space.

- Required electrical parts - circuit breakers, wires, and installation materials.

- Location of control panel.

- The need to retrofit/install the drain, drain length, parts quantity, and assessment of any problems with the drain installation.

\section{Low-Flow Showerhead Information}

- The number of different styles of showers, connection diameter, and quantity of each.

- Water consumption of the showers based on measured consumption, usage statistics, and frequency of use specific to the building.

- Any abnormality in using the showers (hot water availability only during certain periods, restrictions on tap water use, abnormally high/low usage and its reason, etc.).

- Likelihood that showerhead will be removed or damaged.

\section{Faucet Aerator Information}

- Number of water outlets, styles, and connection diameters.

- Water consumption by the water outlets based on measured consumption, usage statistics, and frequency of use specific to the building.

- Any abnormality in using the water outlets (hot water availability only during certain period, restrictions on showers use, abnormally high/low usage and its reason, etc.).

- Likelihood that the faucet aerator will be removed or damaged. 


\section{Appendix B}

\section{Draft Typical Designs}

Five typical designs for substation retrofit equipment that provide for improved temperature control are presented in this discussion with suggested actions for the Committee of Architecture to complete the designs.

In brief, the five alternative designs by type of service follow:

Space Heat

- Heat Exchanger (1)

- 3-Way Valve

Space Heat and Domestic Hot Water

- Separate Heat Exchangers for Space Heat (1) and Domestic Hot Water (2)

- 3-Way Valve for Space Heat and Heat Exchangers for Domestic Hot Water (2)

Space Heat, Domestic Hot Water, and Ventilation

- Separate Heat Exchangers for Space Heat (1), Domestic Hot Water (2), and Ventilation (1) (A 3 -way valve is not considered for this configuration because of the difficulty to control and operate, and a negligible cost advantage.)

The heat exchanger system isolates the building (secondary) circuit from the district heating company supply (primary) circuit, where the 3-way valve system does not.

The typical designs presented in Figures 1 through 5 are drafts and should be used for guidance only at this point. The detailed typical design for each alternative should be reviewed and produced by Ukrainian experts familiar with the design standards and practices for equipment that provides space heat, domestic hot water, and ventilation. Thus, the next steps are for experts from the Committee for Architecture to provide:

1. Expert review of the draft typical design presented in Figures 1 through 5 for completeness of the components, layout, compliance of arrangement with appropriate Ukrainian standards.

2. Preparation of the final typical design CAD drawings that correspond to the typical designs.

3. Preparation of the technical specification for all standard components.

4. Review of the design with the district heating company experts and all involved approval authorities and obtaining consent on the design. 


\section{Description of Alternatives}

\section{Figure 1. Space Heat Only: Heat Exchanger Based System (1)}

The substation is composed of a plate type heat exchanger (1) (or equivalent) and all necessary components. District heat supply water hydraulic parameters are restricted by the orifice (29), which must be removed or re-sized for new system hydraulic conditions. Strainers (23) are installed in both the primary and secondary to protect the heat exchanger. Temperature and pressure readouts are installed in each of the distribution branches for visual inspection. Make-up water for the secondary loop is provided from the district heat primary side through the pressure regulator/feed valve (20) as it is assumed that hot water will not be available at the site. Two circulating pumps (15) are shown in the secondary loop; if only a single pump is required by standards, it is advisable to have spare parts available. The secondary loop must be equipped with expansion tank(s) (27) and pressure relief valve (28). According to U.S. standards, the flow meter (part of the heat meter) (11) should be installed in the return primary line.

\section{Figure 2. Space Heat Only: 3-Way Valve Based System}

This is an open, direct substation, which allows primary water supplied by the district heating system to enter the building's heating system pipes. The heat input to the building is controlled by a 3-way valve (6), which allows the return (colder) water to mix with the primary water. A strainer (23) is installed in the return pipe to prevent debris from the building system entering the 3-way valve.

\section{Figure 3. Space Heat and Domestic Water Heat: Heat Exchanger Based System (2)}

The space-heating loop with the heat exchanger (1) is identical to the system shown in Figure1. The primary return water from the space-heat heat exchanger is directed to the domestic hot water heat exchanger to allow for cooler return water temperature. The domestic hot water heat exchanger consists of two parts, the pre-heater (2) and the after-heater (3). The domestic hot water temperature is controlled by the control unit (8) via modulating valve (5). The domestic hot water heating system assumes water re-circulation with circulating pump (17). The space heating secondary loop is filled through a pressure regulator/feed valve assembly (22) from the domestic hot water loop, not from the district heat primary loop.

\section{Figure 4. Space Heat and Domestic Water Heat: 3-Way Valve Based System for Space Heat and} Heat Exchanger for Domestic Hot Water

This system is a combination of direct system for the space heating and heat exchanger for water heating. The space heat part of the substation system is identical with the one shown in Figure 2, and the domestic hot water part of the substation is identical with that shown in Figure 3.

Figure 5. Space Heat, Domestic Water Heat, and Ventilation: Heat Exchanger Based System (3)

The system for space heat and domestic hot water is identical with that shown in Figure 3 except that the building with ventilation systems will require an additional heat exchanger $(3 \mathrm{~A})$ for heating the ventilation air. The ventilation loop is equipped with an independent controller, modulating valve (7) and circulating pump (18). The primary water is directed first to the space-heat heat exchanger, and then is used for preheating the domestic hot water and in the ventilation heat exchanger. 
Table 1. Description of Components

\begin{tabular}{|l|l|}
\hline No & Part Description \\
\hline 1 & Heat exchanger, space heating \\
\hline 2 & Heat exchanger, preheat, Domestic Water Heating (DWH) \\
\hline 3 & Heat exchanger, after-heat, DWH \\
\hline $3 \mathrm{~A}$ & Heat exchanger, ventilation system \\
\hline 4 & Modulating valve, space heating \\
\hline 5 & Modulating valve, DWH \\
\hline 6 & 3-way valve, space heating \\
\hline 7 & Modulating valve, ventilation heater \\
\hline 9 & Control unit, space heating and DWH \\
\hline 10 & Temperature sensor \\
\hline 11 & Heat meter unit \\
\hline 12 & Indow meter (part of heat meter) \\
\hline 13 & Outdoor air temperature sensor \\
\hline 14 & Control unit, ventilation heater \\
\hline 15 & Circulation pump, space heating \\
\hline 16 & Re-circulating pump \\
\hline 17 & Circulation pump, DWH \\
\hline 18 & Circulating pump, ventilation heater \\
\hline 19 & Check valve (or "no-return valve" or "back-flow preventor") \\
\hline 20 & Pressure regulator/feed valve assembly \\
\hline 21 & Shutoff valve, existing \\
\hline 22 & Shutoff valve \\
\hline 23 & Strainer \\
\hline 24 & Drain valve \\
\hline 25 & Pressure gauge \\
\hline 26 & Thermometer \\
\hline 27 & Expansion tank \\
\hline 28 & Pressure relief valve \\
\hline 29 & Orifice, existing, re-calibrated \\
\hline & \\
\hline
\end{tabular}




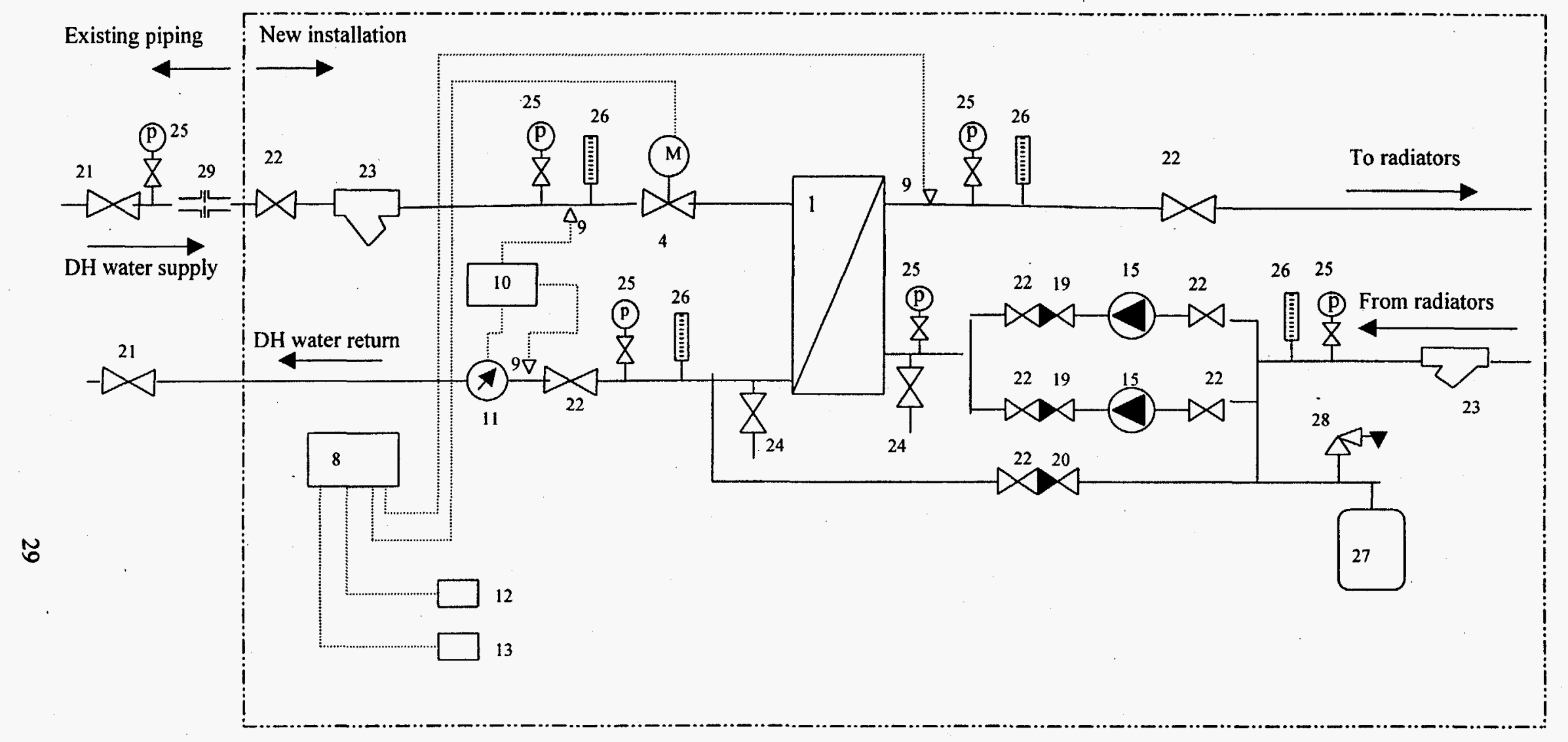

Figure 1. Space Heating System

Heat Exchanger Based System 


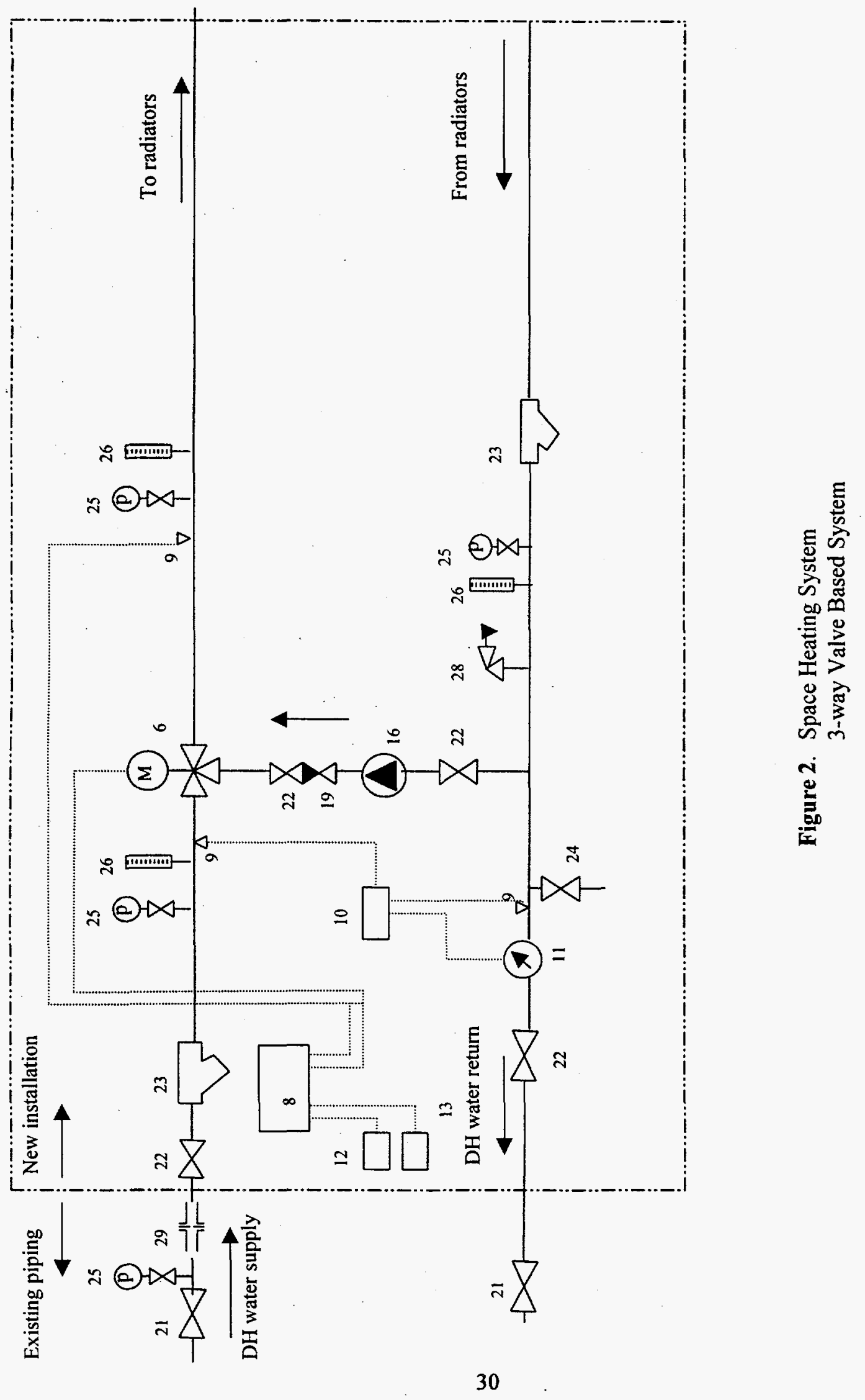




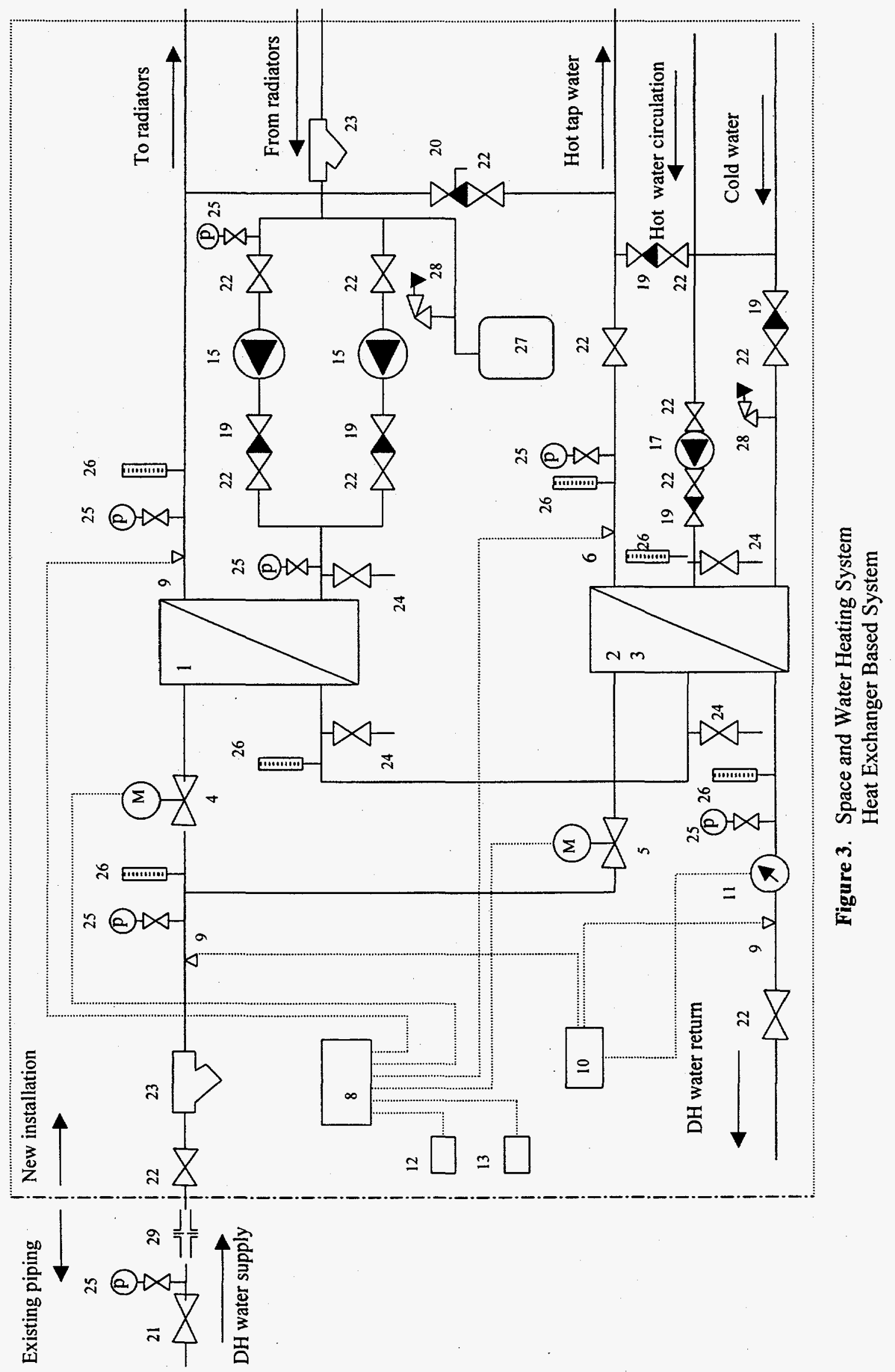




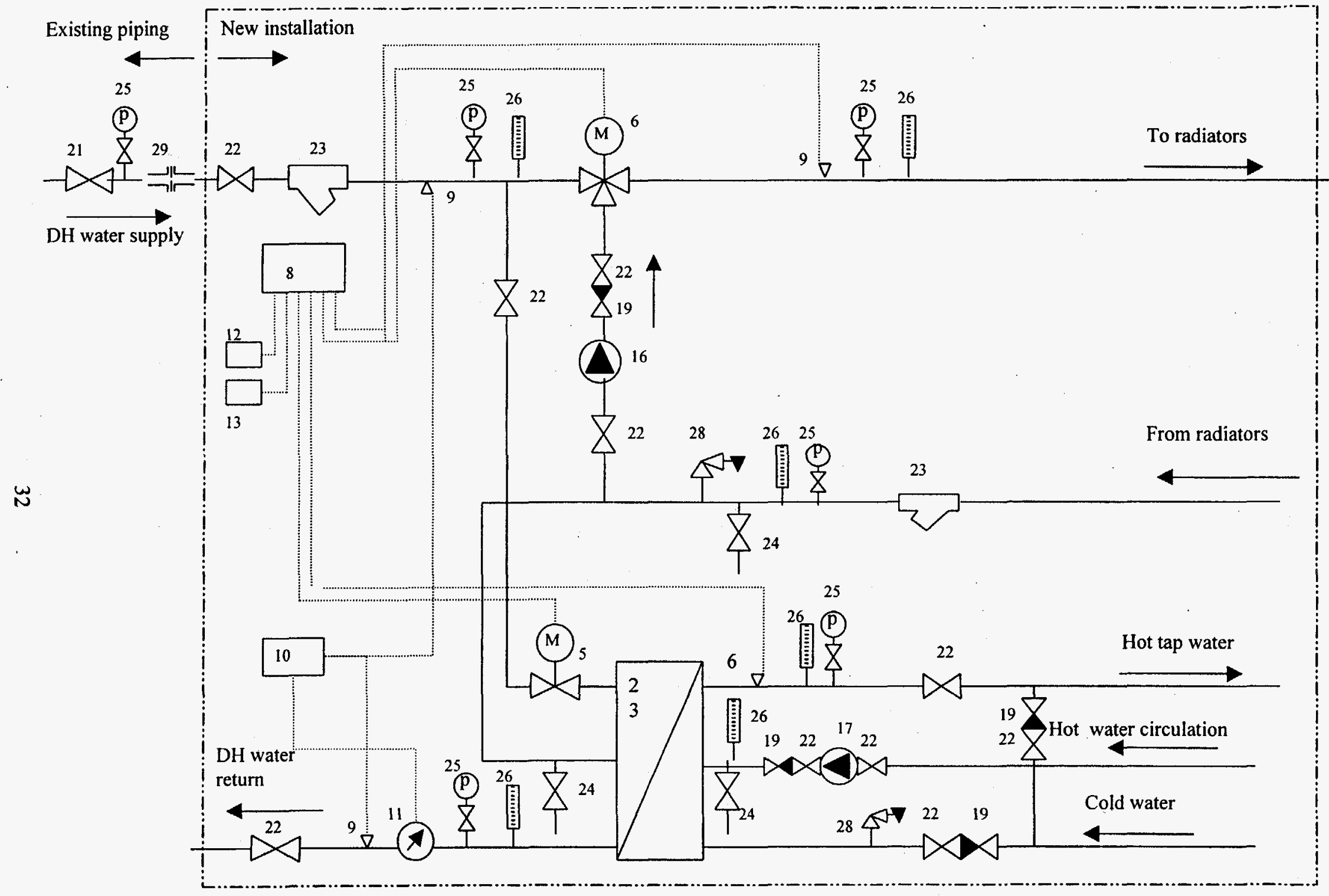

Figure 4 Space and Water Heating System with 3-way Valve for SH and HX for DWH 


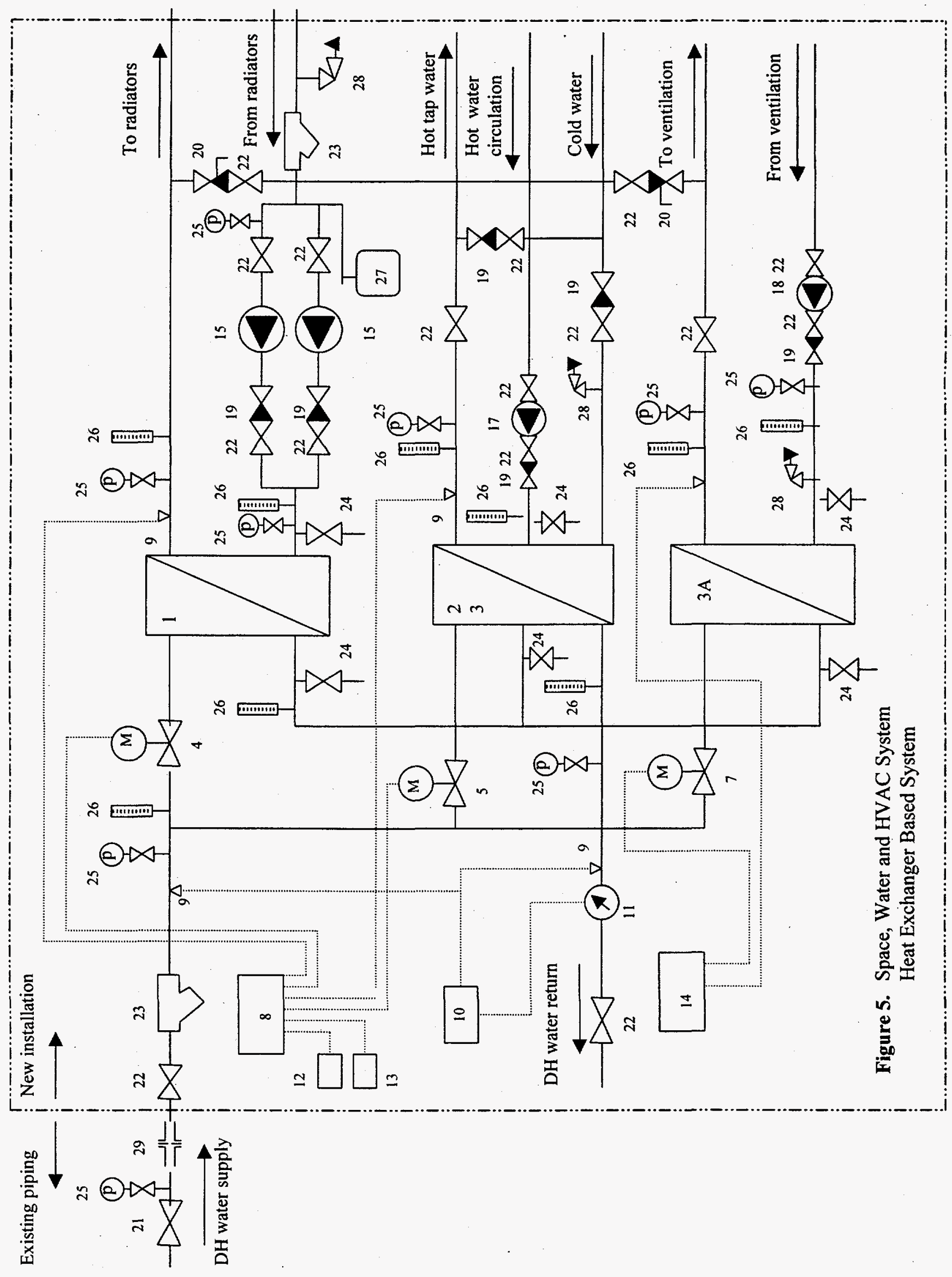

